The following is an examination of trends in foundation giving priorities during times of financial difficulty. It is part of an ongoing Foundation Center research series intended to shed light on the potential impact of the current economic downturn on the nonprofit sector.

\title{
Do Foundation Giving Priorities Change in Times of Economic Distress?
}

As nonprofit organizations brace themselves for the possibility of reduced charitable giving, we have been asked whether specific funding areas may be more vulnerable to cuts than others. For example, do foundations reduce their funding for the arts to increase support for social services, or do they cut back on international giving to address increased domestic demand? Some fear that society in general, and grantmakers in particular, may not place as high a value on staging a new symphony, funding economic development activities in Africa, or preserving green space at a time when domestic unemployment is rising and the social safety net is growing weaker.

While we cannot guarantee that future actions will mirror past behavior, an examination of giving by U.S. foundations during the economic downturn of the early 2000s suggests that overall grantmaking priorities do not shift suddenly in the face of reduced resources and over the longer term are remarkably consistent.

\section{Foundation Giving Trends by Major Field, 1999 to 2005}

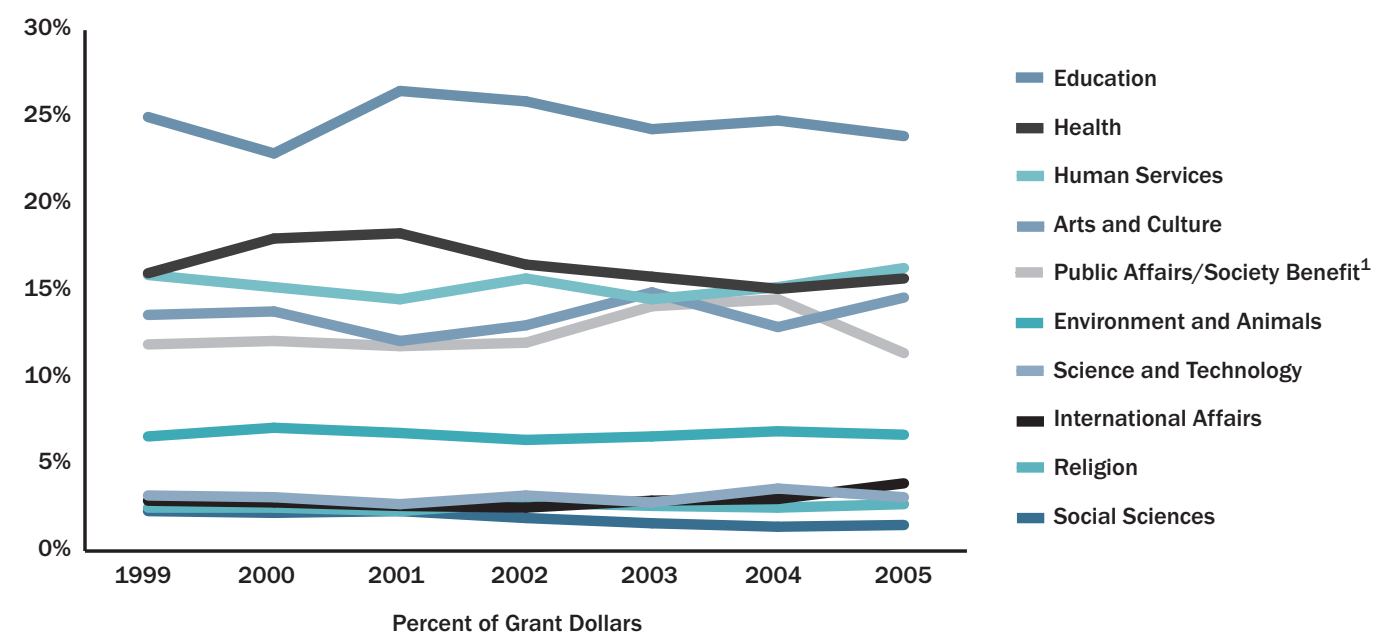

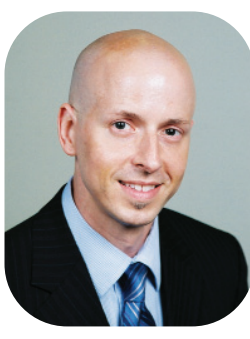

Steven Lawrence Senior Director of Research The Foundation Center 
The Foundation Center analyzed more than 830,000 grants of $\$ 10,000$ or more awarded by over 1,000 of the nation's largest foundations between 1999 and 2005 to see whether there were any significant changes in relative grantmaking priorities across major subject areas during the economic downturn of 2001 to $2003 .{ }^{1}$ While there were some fluctuations during those years in the relative shares of giving in specific subject areas, the fluctuations were no larger than those seen during the years both immediately preceding and following this period. ${ }^{2}$ This suggests that the last economic downturn primarily affected the overall level of foundation giving, rather than funders' broad grantmaking priorities (see our October 2008 research advisory, "Past Economic Downturns and the Outlook for Foundation Giving").

This same pattern of normal fluctuations in share of total giving held true for international grantmaking. The share of giving for international purposes remained relatively steady from 1999 to 2005 , despite increased government regulation of international giving in the aftermath of September $11 .^{3}$

These findings based on field of activity and geographic focus should not be taken to mean that the specific grantmaking initiatives of 1999 are identical to those of 2005. Rather, they suggest that these foundations have a steady commitment to mission and grantmaking priorities and guidelines. In times of financial hardship, this may mean that an arts organization stays open when attendance is down, or more land is conserved when property is less expensive, or improvements in global health are not deferred until the stock market recovers.

Does this mean that foundations are unresponsive to pressing demands outside of their core focus areas during times of exceptional need? In fact, the evidence suggests quite the contrary. The Foundation Center documented almost $\$ 700$ million in giving by U.S. foundations

\section{International Giving's Share of Overall Foundation Giving,} 1999 to $2005^{1}$

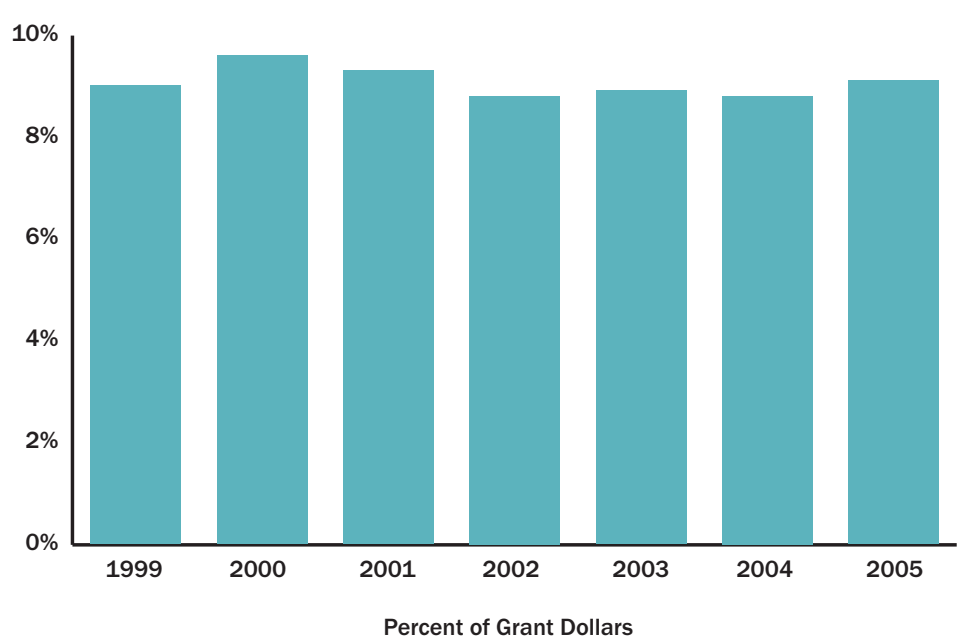

SOURCE: The Foundation Center, 2008. Based on all grants of $\$ 10,000$ or more authorized or paid (if authorized figures are unavailable) by a sample of over 1,000 of the largest U.S. foundations in their 2006 fiscal year. Figures exclude giving by the Bill \& Melinda Gates Foundation.

${ }^{1}$ Includes grants awarded to overseas recipients and U.S.-based international programs.

in the aftermath of the September 11 terrorist attacks ${ }^{4}$ and close to $\$ 500$ million in funding through mid-2007 for relief, recovery, and rebuilding efforts following the 2005 Gulf Coast hurricanes. ${ }^{5}$ In lieu of cutting back on support for existing funding priorities, foundations may use discretionary or emergency funds to make these commitments, or even tap their endowments.

As of early November 2008, a number of foundations have already announced efforts to specifically address the current economic crisis. Among these are the MacArthur Foundation's $\$ 68$ million initiative to provide grants and low-interest loans for foreclosure prevention and mitigation efforts in Chicago neighborhoods; the Alfred P. Sloan Foundation's initial $\$ 2.7$ million in funding as part of a new initiative to study the ongoing financial market crisis and improve public understanding of economics and finance; and the Silicon Valley Community Foundation's additional \$1 million commitment to its new "Strengthen the Safety Net” campaign.
No one can successfully predict how long the current financial crisis will last, how deep the recession will be, and what toll this will take on the grantmaking capacity of the nation's foundations. But the relative stability of foundations' grantmaking priorities during the last economic downturn should alleviate at least one source of concern for nonprofit organizations as they face the challenging times ahead.

\footnotetext{
${ }^{1}$ This analysis is based on the full value of grants authorized or paid (if authorized amounts are unavailable) by sampled foundations in their fiscal years corresponding to the years of analysis. It excludes giving by the Bill \& Melinda Gates Foundation, to avoid possible distortions in historical trends resulting from the ramping-up of giving by the nation's largest grantmaker. Therefore, statistics will differ somewhat from those presented in annual editions of the Foundation Center's Foundation Giving Trends: Update on Funding Priorities.

${ }^{2}$ Funding for the social sciences represented one obvious exception, but the field has been experiencing a loss in share of grant dollars over the past two decades. In 1989, funding for the field totaled 3.4 percent of grant dollars in the sample.

${ }^{3}$ See the Foundation Center's report, International Grantmaking III: An Update on U.S. Foundation Trends.

${ }^{4}$ See "Giving in the Aftermath of September 11: Final Update on the Foundation and Corporate Response" included in the Foundation Center's report, September 11: The Philanthropic Response, available at foundationcenter.org.

${ }^{5}$ See the Foundation Center's study, Giving in the Aftermath of the Gulf Coast Hurricanes: Update on the Foundation and Corporate Response, available at foundationcenter.org.
} 